\title{
ASCENDING AORTIC ANEURYSM, WANDERING TOWARDS OLD PROBLEM WITH NEW INSIGHT
}

Tiwari KK ${ }^{1}$, Bevilacqua $\mathrm{S}^{2}$, Salvati $\mathrm{A}^{3}$, Varone $\mathrm{E}^{2}$, Solinas $\mathrm{M}^{2}$, Glauber $\mathrm{M}^{2}$

\begin{abstract}
Ascending aortic aneurysm is a silent and highly lethal disease. Generally, ascending aorta grows asymptomatically until it dissect or rupture. In case of acute complication mortality is as high as $90 \%$, whereas if treated on time mortality and morbidity decreases significantly. Pathophysiology of the Ascending aortic aneurysm is a complex process. Aorta itself is an organ and it should not be considered merely as a tube transporting blood from heart to the organs. Several non-invasive and invasive imaging methods are available at disposition to diagnose this indolent killer at early stage. However, discrepancies exists about when to operate these patients. Several other methods has been reported to identify these patients at risk of dissection or rupture. Conservative treatment could be used in patients with small aortic diameter, but effectiveness of such approach is under scrutiny. Emerging endovascular treatment using stents should be advocated with caution. Surgical treatment, the gold standard, is recommended for asymptomatic patients with aortic diameter of $5.5 \mathrm{~cm}$, whereas $4-4.5 \mathrm{~cm}$ for patients with Marfan's disease. Postoperative morbidity and mortality has significantly decreased due to better anesthetic management, improved surgical techniques and progress in preoperative and postoperative care.
\end{abstract}

KEYWORDS : Ascending aortic aneurysm

1. Department of CTVS, College of Medical Sciences Teaching Hospital, Bharatpur, Nepal

2. Department of Adult Cardiac Surgery, G. Pasquinucci Heart Hospital, Massa, Italy

3. The Salam Center for Cardiac Surgery, Khartoum Sudan

For Correspondence

Dr. Kaushal K. Tiwari M.D., M.S., I.M.C.S., Ph.D.

Department of CTVS

College of Medical Sciences Teaching Hospital

Bharatpur, Nepal

Email:drkaushalkt@yahoo.com 


\section{BACKGROUND \\ Epidemiology}

Cardiovascular diseases are one of the most important cause of death in the majority of developed countries. Cardiovascular morbidity and mortality are in rise in many developing countries. Among cardiovascular pathologies, aortic aneurysms probably represent the most lethal and indolent enemy of the medical community. Usually, they silently and asymptomatically grow up until an acute and often catastrophic complication occurs. The threats of a nonoperated aortic aneurysm include dissection or rupture of the aorta, subsequently leading to death. In contrast, despite the armamentarium of modern perioperative and post-operative cardiac surgical care, the risk of surgery include paraplegia, stroke, bleeding, and mortality ranging from 3 to $9 \%$ after elective surgery. Conversely, in cases of acute events mortality can be as high as $90 \%$. In the United States, aortic aneurysms (thoracic and abdominal) constitute the $17^{\text {th }}$ leading cause of death in the general population and the $15^{\text {th }}$ for individuals older than 65 years. Approximately 15,000 individuals die every year from this pathology in the United States of America, which is more than death caused by HIV infection. Even if less frequent than abdominal aneurysm, thoracic aortic aneurysms (TAAs) have a reported incidence of about 10 cases per 100,000 patients/year, with a yearly risk of rupture or dissection of $7 \%$. Significant heterogeneity occurs in distribution of aneurysm disease along the aorta, with $50 \%$ of all TAA involving the ascending aorta, $10 \%$ the arch, and $40 \%$ the descending aorta ${ }^{2,3}$ (Figure 1 ).

Cumulative and yearly risks of aortic dissection and rupture increase as the aneurysm size increases. Incidence of dissection in female patients have been shown to be higher than male, which could be due to a given aortic diameter representing proportionally greater dimension in smaller women. In front of a similar distribution of TAA between sexes, $79 \%$ of acute complications inexplicably occur in women".

Figure 1: Anatomic localization of TAA

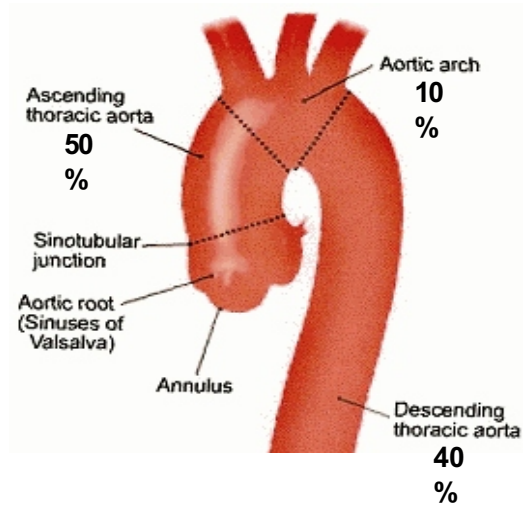

\section{Definition}

Aortic aneurysm can be defined as a localized undue dilation with $50 \%$ increase in size over the normal diameter. The "normal diameter" strictly depends on age, sex and body size, as well as the anatomical localization of the affected aorta. For the physiologically smaller abdominal aorta, the term aneurysm is usually limited to diameters exceeding $30 \mathrm{~mm}$, while, on the contrary, a TAA should be conventionally larger than $40 \mathrm{~mm}$. According to Elefteriades J, ascending aortic aneurysm are divided into three categories, according to the pattern of the involvement of the aortic root. These are supracoronay aneurysm, annuloaortic ectasia (Marfanoid) and tubular diffuse enlargement of the aorta. (Figure 2)

Figure 2: Types of ascending aortic aneurysms

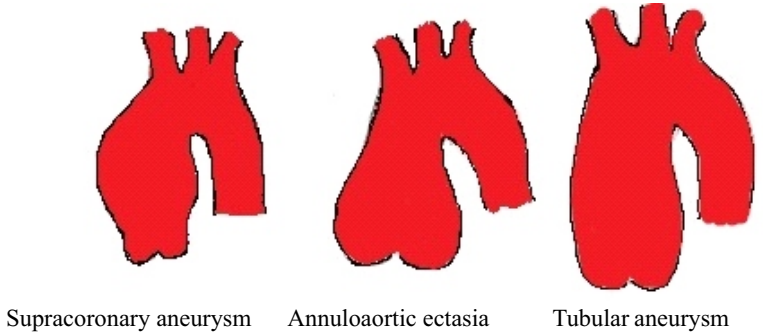

\section{Symptoms}

Patients with a TAA are usually asymptomatic and diagnosed by chest X-rays or CT-scan requested for other reason. Thoracic aortic aneurysm can cause symptoms by compressing nearby structure. Hoarseness of voice could be a presenting symptom if it compresses recurrent laryngeal nerve; stridor, dyspnea from tracheal, bronchial or lung compression; dysphagia from esophaseal compression; and plethora and edema, from superior vena cava compression. A dull and vague pain in neck and jaw may be an indication of aortic arch aneurysms, while back, interscapular, and/or left shoulder pain may occur with descending aortic aneurysms. dissects or ruptures. Frequently, patients present with sign and symptoms of aortic insufficiency, which ought to be the main reason behind patient coming to clinical attention. Ultimately, acute syndrome including aortic dissection or aortic rupture, if could make to the hospital, might present with potentially lethal outcomes.

\section{Pathophysiology}

Pathophysiology of ascending aortic aneurysm is complex. Risk factors for the development of thoracic aortic aneurysms include hypertension, smoking, and chronic obstructive 
pulmonary diseases. Ascending aortic aneurysms are also related with bicuspid aortic valve. Additionally, several genetic syndromes with a predisposition for ascending aortic aneurysms have been identified. Most common genetic diseases effecting thoracic aorta are: Marfan Syndrome, Loeys-Dietz Syndrome, Ehler-Danlos Syndrome, Turner Syndrome, familial thoracic aortic aneurysm Syndrome, and still others are idiopathic.

Historically, it was supposed that aortic dilation and strength reduction of the aneurysmatic aortic wall were exclusively related to primary connective tissue alterations. Recent data support that aortic wall remodeling is a dynamic process with active involvement of the immunological system and smooth muscle cells (SMCs). TAA formation and progression is a multifactorial process that involves both cellular and extracellular Mechanism.

\section{Figure 3: The pathogenesis of TAA basically involves four} essential mechanisms

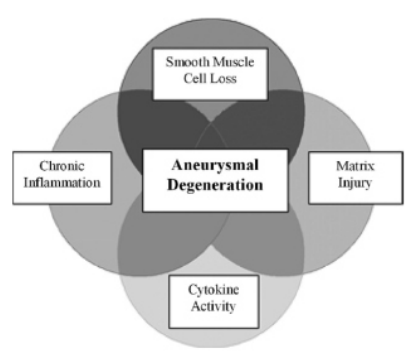

\footnotetext{
$\checkmark$ extracellular matrix proteolysis

$\checkmark$ chronic inflammation

cytokine activity

$\checkmark$ smooth muscle cell(SMC) loss
}

These four mechanisms interact to undermine the integrity of the aortic wall leading to aneurysm formation, growth, and, ultimately dissection or rupture.

\section{Histopathology}

Pathologically, cystic medial necrosis and lamellar medial necrosis are found in the arterial wall of the dissected aorta with helicoids hypertrophy of the collagenous fibers, rarefaction and fragmentation of the elastic fibers in the tunica media. It has shown that there are abnormalities in collagen and elastin in the tunica media of the dissected aorta. The pathological findings of patients without Marfan syndrome show rupture and decrease in elastic fibers in the tunica media. Thus, it is considered that fragility of the tunica media is still a cause of aortic dissection in patients without Marfan syndrome. According to Illiopoulos and co-authors the ascending aortic tissue undergoes major wall remodeling on diameter enlargement, with the decrease in media partly compensated by an increase in intimal thickness. They have also found that elastin and collagen area densities decreased in the media layer of TAA specimens as compared to control specimens. Furthermore, they have reported a decreased elastin density in the intima and entire wall of TAA and an increased collagen density in the adventitia and an invariant density in the entire wall. Decrease elastin content substantiate the deficient extensibility of ascending aortic aneurysm.

The extracellular matrix (ECM), which is made of the same elastic fibers and collagenous fibers that exist in the tunica media, plays a role in maintaining the shape of the aortic wall. The matrix metalloproteinases (MMP) are a heterogenous family of enzymes that, altogether, are capable of degrading all the constituents of the ECM. They are required for normal development and for general turnover of the ECM, but are elevated in many pathological conditions including inflammatory diseases. MMPs are tightly regulated at three main points, transcription, activation, and inhibition. All of them are secreted in a proform, which requires initial activation by another proteinase, and once activated, there are at least four specific MMP inhibitors (tissue inhibitors of Metalloproteinase, or TIMPS), which can bind them irreversibly.

The role of MMP-2 (Gelatinase A) and MMP-9 (Gelatinase B) in the development of aortic aneurysm has been extensively studied. MMP-2 and MMP-9 generated in the macrophages cut the type IV collagen in the elastic fibers and basement membrane, and break the tunica media of the aortic wall, resulting into a fragile and enlarged aorta. MMP-9 is also produced by fibroblasts or SMCs that have been stimulated to undergo a phenotypic switch favouring synthetic activity. Most of the studies showed the role of MMP-2 in abdominal aortic aneurysm, whereas the contribution of MMP-2 to the development of TAA is not fully defined. Studies focusing on idiopathic TAAs have failed to show an increase in MMP-2 levels compared to normal aortas.

MMPs degrade the structural proteins of the aortic wall. These enzymes are normally antagonized by TIMPs and fibrillin-1 gene. Recently, it has been demonstrated an excessive lysis of matrix in ascending aortic aneurysms and dissections. It is hypothesized that aneurysm patients are genetically prone to 
excessive MMPs activity, leading ultimately to degradation and thinning of the aortic wall with subsequent increase of the aortic diameter and aneurysm formation.

\section{Inflammatory and immune mechanism}

Inflammatory cells like monocytes, macrophages, plasma cells, B-lymphocytes, and T-lymphocytes actively participate in the genesis of aneurysms. Tang et al. suggested that the outward vascular remodeling and intimal expansion of TAA correlate with the extent of a Th1 immune response ("IFN-y driven") ${ }^{11}$, which causes production of cytokines such as IFN$\gamma$, TNF- $\alpha$ and various chemokines, all contributing to leukocyte recruitment, cell-mediated inflammation and tissue damage.

\section{Biomechanical property of the aorta}

Result of above mentioned pathophysiological processes lead to alteration of one of the important property of the aorta, i.e. biomechanical property. Biomechanical properties of the aorta may have additional value regarding the occurrence of aortic dilatation, dissection, and rupture in aortic degenerative disease and may contribute to the risk stratification of patients at risk for aortic complications. The ultimate goal in the care of a patient with an aortic aneurysm is to prevent rupture, a material failure that occurs when the aortic wall stress exceeds the tensile strength. According to the law of LaPlace, wall tension is influenced by intramural pressure, vessel diameter, and wall thickness, and the application of this tension to a defined area indicates wall stress. Therefore, the aorta, we are realizing, is "much more than a tube", as stated by a pioneer in the study of ascending aortic aneurysm pathology. It is more complex than passive, hollow conduit for delivery of blood to the vital organs. Aorta is rather to be considered as an organ itself, with complex histological structure and intrinsic biology, which dynamically interact to create a sophisticated mechanical bio-machine that works to optimize ventricular work and control delivery of blood and signals to tissues. The material properties of the normal and aneurismal aorta with regard to breaking stress and distensibility or stiffness have been an area of intense study.

Once aneurysm formation is initiated, it is associated with destructive remodeling of the aortic wall, the time course of which is characteristic of steady structural deterioration, radial enlargement, rearrangement of hemodynamic loads, and ultimately rupture. The biomechanical behavior of arterial tissue is generally attributed to the status of the structural proteins present. Elastin provides distensibility and recoil at lower pressures, whereas collagen provides tensile strength and stiffness at higher pressures. Loss of elastic fibers and derangements in collagen cross-linking seems to be involved in the TAA. Aneurysm rupture is a biomechanical failure that occurs when the stresses exerted on the aortic wall by hemodynamic loads exceed the tissue's capacity to sustain stress. Knowledge of the mechanical properties of aortic aneurysms, together with their individual geometry, is vital in predicting their risk of rupture. Biomechanical properties of the aorta can be expressed in terms of distensibility (percentage of luminal increase per pressure increase \{in millimeters of mercury\}during a heart beat cycle) or the propagation velocity of the pulse or flow wave through the aorta (pulse wave velocity, flow wave velocity propagation)". Koullias and colleagues offered an estimate of the in vivo mechanical properties like distensibility, aortic wall stress and Incremental elastic modulus of TAA. Okamoto and associates examined the in vitro properties (opening angle, biaxial elastic, and uniaxial circumferential strength tests) of dilated ascending aorta, and Vorp and coworkers compared the biomechanical properties (Maximum tissue stiffness and tensile strength) of TAA with respect to the non-aneurismal aorta, reporting lower strength and higher stiffness on the former. A change in aortic radius caused by an incremental change in pressure describes vessel distensibility, and a lack of distensibility or resistance to deformation is referred to as stiffness. Aortic distensibility decreases with increase in aortic diameter, which emphasize aortic stiffness as a potential predictor of aortic dilatation and aortic dissection in Marfan patients. Several studies evaluated by echocardiography and MRI have demonstrated increased aortic stiffness in TAA patients'.

There has been strong evidence from many reports that the mechanical properties and strength of aortic wall tissue show pronounced age dependency. In particular, Okamoto and colleagues reported a negative correlation of failure stress with age for the dilated ascending thoracic aorta, whereas same finding for the healthy descending aorta has been demonstrated in several other studies ${ }^{81,89}$. Other studies also disclosed that the aorta becomes less extensible and stiffer as a result of aging.

\section{DIAGNOSIS}

\section{Instrumental evaluation of the ascending aorta}

For the diagnosis of aortic aneurysm several diagnostic tools are available ranging from non-invasive examination ( Chest $\mathrm{X}$-ray, Echocardiography, Computed tomography and MRI) to invasive examination like angiography. Noninvasive imaging is essential for assessment of aortic size and in some 
cases functional parameters. It is important to know the accurate size of the aorta because key decisions regarding management of the aortic aneurysm depend on size.

\section{Chest X-Ray}

Chest X-ray often performed as a part of general examination in patients with potential cardio-pulmonary disease. It sporadically detects abnormalities of aortic contour or size that require definitive aortic imaging.

\section{Echocardiography}

Echocardiography is one of the most used imaging modality in the cardiology, which has a high sensibility and specificity in diagnosing variety of cardiac pathology including ascending aortic aneurysm. Transthoracic echocardiography (TTE) is more readily available, easy to use, transportable and cost effective. No need of contrast and sedation make it as a first line diagnostic tool in clinical set up. However, transesophageal echocardiography (TEE) is superior to TTE and more accurate for assessment of the thoracic aorta, but sometime requires sedation and has a small risk of complications like esophageal perforation (less than $0.03 \%$ ). In addition, with diagnosis of aortic dilatation, echocardiography may reveal other associated pathology that suggests the underlying etiology of the aortic disease (eg, bicuspid aortic valve). Nevertheless, for accurate evaluation of ascending aortic aneurysm and to confirm the indication for surgery, there are some restrictions. TTE and TEE are user dependent. TTE can only visualize the proximal part of the ascending aorta, thus it can miss an aneurysm of the midportion of the ascending aorta. Even TEE is limited by the interposed tracheal air column and can be "blinded" to the upper portion of the ascending aorta. Furthermore, there is no universal agreement for exact place of aortic diameter measurement and whether the aortic wall should be included or excluded in the aortic diameter measurement.

\section{CTScan}

New generation helical CT scan has a sensitivity up to $100 \%$ and specificities of $98 \%$ to $99 \%$ for diagnosing abnormalities of the thoracic aorta. IRAD data shows that in some centers, CT has been used more frequently than Echo in case of aortic dissection. Major advantages of CT scan are: very wide availability, ability to image entire aorta, including lumen, wall and periaortic region. Additionally, CT scan is more or less exact in the size measurement, and it has a shorter examination time. Three dimensional reconstruction of CT images has an important role in the planning of surgery.
However, a CT scan with axial images cannot properly evaluate the very proximal portion of the ascending aorta. In addition, motion artifact can adversely affect the resolution of CT images of the aorta, although technology is improving, especially with ECG gated tomographic angiography. Furthermore, risk of renal damage from the contrast media used during CT scan is a real obstacle in some patients.

\section{Angiography}

The shape of the aorta is ideally seen angiographically. Images of the aortic contour are exceptional and morphology of the aortic can be seen beautifully. This can facilitate accurate surgical planning. Additionally, it allow for evaluation and treatment of coronary artery disease, aortic branch disease, as well as assessment of aortic valve and left ventricular function. ${ }^{97}$ However, diameter of the ascending aorta from the angiographic images is not always accurate and simple to calculate. It is not available universally because it requires the presence of experienced physician to perform. It has disadvantage of being invasive procedure that is time consuming and require contrast medium with exposure to radiation.

\section{Magnetic Resonance Imaging}

Magnetic resonance imaging (MRI) has been recommended as the technique of first choice for the detection and follow-up of both aortic complications and premorbid conditions, such as intramural hematoma, and aortic aneurysm. Its other advantages are ability to assess branch artery involvement, diagnosing aortic valve pathology, and left ventricular dysfunction. MRI is inherently a multiplane modality that can provide high quality images of the aorta in transverse, axial, sagittal, and coronal plane, as well as in left anterior oblique view. MRI has shown high sensibility and specificity both for initial diagnosis and progression of aneurismal disease. MRI offers a non-invasive and accurate evaluation of TAA and it doesn't require nephro-toxic contrast agent or ionizing radiation, although it takes longer time to acquire images and might need sedation in some patients and is not widely available in an emergency basis. ${ }^{39,42}$ It is also contraindicated in claustrophobic patients, and patients with metallic prosthesis and pacemakers. Use of cine-MRI techniques, combined to non-invasive haemodynamic data, offers both a morphological and functional examination of the entire aorta, which can provide with information about diameter, geometry, blood flow and aortic wall mechanical properties. ${ }^{44}$ 


\section{Functional MRI Examination}

Most of the study to evaluate ascending aorta using functional MRI has been done in Marfan patients or patients with bicuspid aortic valve. ${ }^{35}$ However, its role in evaluating biomechanical property of the ascending aorta in other patients could be valuable as well. Information supplied by functional MRI may have utility in thoracic aortic disease management. Important parameters evaluated by functional MRI are:

\section{Aortic distensibility}

The ratio of aortic diameter (or area or volume) and pulse pressure yields a derivative for in vivo measurable stiffness, called aortic distensibility. ${ }^{34}$ Aortic distensibility can be calculated using functional MRI. To calculate it following formula is used.

\section{$\mathrm{D}=(\mathrm{A} \max -\mathrm{A} \min ) /[\mathrm{A} \min \mathrm{x}(\mathrm{P} \max \mathrm{P} \min )]$}

$\mathrm{D}=$ distensibility $\left(10^{-3} \mathrm{mmHg}^{-1}\right), \mathrm{A} \max =$ maximal (systolic) aortic area $\left(\mathrm{mm}^{2}\right), \mathrm{A} \mathrm{min}=$ minimal (diastolic) aortic area $\left(\mathrm{mm}^{2}\right), \quad \mathrm{P} \max =$ systolic blood pressure $(\mathrm{mmHg}), \quad \mathrm{P}$ $\min =$ diastolic blood pressure $(\mathrm{mmHg})$.

Previous studies have shown significantly decrease distensibility of non dilated ascending aorta in Marfan syndrome and bicuspid aortic valve patients when compared to healthy subjects ${ }^{34,35}$. In addition, increasing size of ascending aorta has inverse relationship in determining the distensibility of the aorta.

\section{Four dimensional flow study}

Given that flow phenomena are important in the hemodynamic etiology of various vascular pathologies, the presence of these flow abnormalities, e.g. blood acceleration, and degradation of measurement accuracy is important to evaluate using functional MRI. The concurrent presentation of $4 \mathrm{D}$ velocities and acceleration data demonstrates the potential of this technique to provide a comprehensive measurement of the proximal cardiovascular hemodynamic environment.

\section{Maximal rate of Systolic distension and diastolic recoil}

Recently, Aquaro et al has evaluate elastic properties of ascending aorta in young patients under 25 years of age with bicuspid aortic valve using MRI and proposed two new functional MRI indexes, maximal rate of systolic distension (MRSD) and maximal rate of diastolic recoiling (MRDR). As suggested by authors, MRSD is an expression of vessel distension during systole whereas MRDR represents diastolic recoil of the aorta. In these patients with bicuspid aortic valve, a significantly slow MRSD and MRDR has been observed suggesting impaired elastic property of the aorta independent of aortic diameter (Figure 5).

\section{Figure 5: MRSD and MRDR in BAV patients compared to control patient. (Aquaro et al.)}
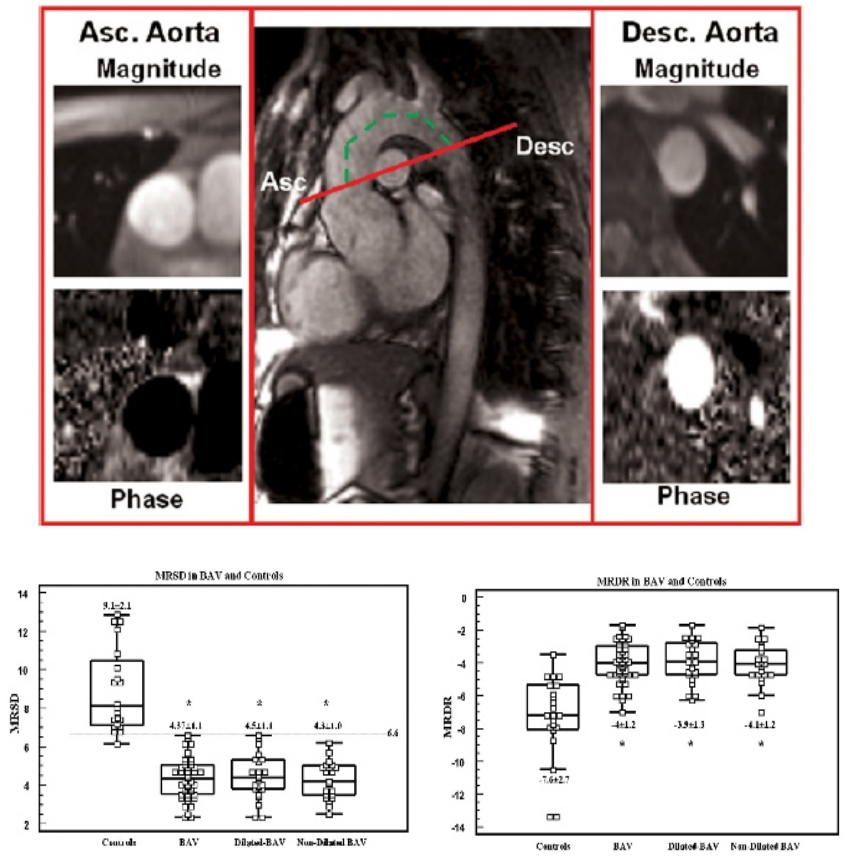

\section{TREATMENT}

Gold standard for treatment of the ascending aortic aneurysm is the surgical treatment. However, conservative treatment could be advised at the initial stage with smaller aortic diameter and in patients with morbidity, high risk factors for negative surgical outcome and who are not suitable for surgical treatment due to other coexisting disease.

In adult patients, conservative managements consist of smoking cessation, life style modification, a stringent control of hypertension, lipid profile optimization, and other measure to reduce risk of atherosclerotic process. Furthermore, several other medical treatment options have been studied. Shores et al. in a randomized control study showed that Marfan patients treated daily with Propranolol has slowed aortic root dilation (0.023 vs 0.084 per year). In a recent randomized trial, angiotensin receptor blocker, losartan, added to beta blocker in a group of pediatric population with Marfan syndrome shows more effective protection to slow the progression of aortic root 
dilatation. Additionally, a matrix metalloproteinase inhibitor, antibiotic doxycycline has shown promising effect in the slowing down of the growth rate of the abdominal aortic aneurysm', but no study has reported effect of doxycycline on ascending aortic aneurysm. To summarize it, none of the studies has shown proven clinical benefit of these medical therapy in the treatment of ascending aortic aneurysm.

Indications For Surgery

If medical therapy can have a palliative role only in high-risk cases, TAA surgery significantly improves 2-year survival from $24 \%$ in un-operated patients to $70 \%$ in patients undergoing aortic replacement surgery.

All together indications for TAA surgery can be divided into two broad categories. ${ }^{9}$

1. Mandatory indication it includes emergency situations as acute dissection, rupture and intramural haematoma and entails immediate treatment at the time of diagnosis.

2. Elective indication this is basically prophylactic in nature, it is reserved to chronic aneurysm and aims to avoid occurrence of acute, devastating complications.

In the light of currently available surgical techniques, myocardial protection strategies and anesthesia management, elective TAA surgery shows low operative mortality with significant improvement of prognosis at long-term follow-up. Recent series reported an operative mortality of 3-4\% for elective operations". This progressive improvement in clinical outcome, during the last two decades, has led surgical community to a revision of the "classic" timing for elective surgery, suggesting more liberal and early indication.

In modern surgical practice, indication for elective TAA surgery depends on two instrumental parameters:

- Absolute diameter of aorta at the time of evaluation.

Yearly growth rate of aortic diameter, independently from absolute diameter.

\section{Absolute Aortic diameter}

Absolute aortic size is a key determinant of diagnostic classification and therapeutic management of patients with thoracic aortic aneurysms. Clinical and instrumental criteria to indicate TAA surgery in daily practice actually vary among different surgical centers, according to their experience and operative results. A temporal evolution, towards more aggressive and individualized treatment, has been observed during the last 10-20 years. Elefteriades et al advocated "prophylactic" surgery at the diameter of $55 \mathrm{~mm}$ for ascending aorta and $65 \mathrm{~mm}$ for descending aorta aneurysms. ${ }^{9}$ This cut-off diameters still represent the most used referral indications for surgery in nowadays practice. Later studies tried to relate surgical timing to patient's characteristics that are known to modify the referral range for "normal diameter" (as body surface area, sex and age) or influence the risk of sudden complications (aneurysm etiology, familial history of rupture or dissection, concomitant valve incompetence, etc). Ergin and co-workers suggest the ratio between measured diameter/predicted diameter (according to sex, age and body surface area) to be more effective than absolute size evaluation for surgical timing. ${ }^{9}$ Concomitant risk factors for rupture or dissection (Marfan syndrome, bicuspid aortic valve, severe aortic regurgitation, aneurysm-related death in familial history, female sex, etc) usually lead to an earlier indication to surgery, with aortic ratio between 1.3 to 1.4 . $^{9}$ Body mass index also affected aortic diameter by $0.27 \mathrm{~mm}$ $(0.14$ to $0.44 \mathrm{~mm})$ per unit of body mass index. Taking into consideration of these evident, in 2006, the group from Yale University proposed a new parameter for better stratifying TAA patients according to the risk of rupture, dissection or aneurysm related death: an "Aortic Size Index (ASI)" (aortic absolute diameter / body surface area) of $2.75 \mathrm{~cm} / \mathrm{m}^{2}$ or more should prompt to elective TAA surgery to avoid moderate to severe (8-20\%) yearly risk of adverse events (Table 1$).{ }^{103}$ By proportional hazard analysis of rupture, they have shown that the risk of rupture is 11 times higher with aortic size index 4.25 to $4.99 \mathrm{~cm} / \mathrm{m}^{2}$ than with ASI 2.00 to $2.74 \mathrm{~cm} / \mathrm{m}^{2}$. This means that, in contrast to "classic" indications, smaller patients may benefit from operative repair at even smaller sizes. For example, a $45 \mathrm{~mm}$ aneurysm in a small lady, with body surface area (BSA) of $1.4 \mathrm{~m}^{2}$, should be nowadays surgically treated. ${ }^{96}$

Table 1: Aortic Size Index chart ( Davies et al.)

\begin{tabular}{|c|c|c|c|c|c|c|c|c|c|c|}
\hline \multirow[b]{2}{*}{ BSA } & \multicolumn{10}{|c|}{ Aortic size $(\mathrm{cm})$} \\
\hline & 3.5 & 4.0 & 4.5 & 5.0 & 5.5 & 6.0 & 6.5 & 7.0 & 7.5 & 8.0 \\
\hline 1.30 & 2.69 & 3.08 & 3.46 & 3.85 & 4.23 & 4.62 & 5.00 & 5.38 & 5.77 & 6.15 \\
\hline 1.40 & 2.50 & 2.86 & 3.21 & 3.57 & 3.93 & 4.29 & 4.64 & 5.00 & 5.36 & 5.71 \\
\hline 1.50 & 2.33 & 2.67 & 3.00 & 3.33 & 3.67 & 4.00 & 433 & 4.67 & 5.00 & 5.33 \\
\hline 1.60 & 2.19 & 250 & 2.80 & 3.13 & 3.44 & 3.75 & 4.06 & 4.38 & 4.69 & 5.00 \\
\hline 1.70 & 2.05 & 2.35 & 2.65 & 2.94 & 3.24 & 3.53 & 3.82 & 4.12 & 4.41 & 4.71 \\
\hline 1.80 & 1.94 & 2.22 & 2.50 & 2.78 & 3.06 & 3.33 & 3.61 & 3.89 & 4.17 & 4.44 \\
\hline 1.90 & 1.84 & 2.11 & 2.37 & 2.63 & 2.89 & 3.16 & 3.42 & 3.68 & 3.95 & 4.22 \\
\hline 2.00 & 1.75 & 2.00 & 2.25 & 2.50 & 2.75 & 3.00 & 3.25 & 3.50 & 3.75 & 4.00 \\
\hline 2.10 & 1.67 & 1.90 & 2.14 & 2.38 & 2.62 & 2.86 & 3.10 & 3.33 & 3.57 & 3.80 \\
\hline 2.20 & 1.59 & 1.82 & 2.05 & 2.27 & 2.50 & 2.72 & 2.95 & 3.18 & 3.41 & 2.64 \\
\hline 2.30 & 1.52 & 1.74 & 1.96 & 2.17 & 2.39 & 2.61 & 2.83 & 3.04 & 3.26 & 3.48 \\
\hline 2.40 & 1.46 & 1.67 & 1.88 & 2.08 & 2.29 & 2.50 & 2.71 & 2.92 & 3.13 & 3.33 \\
\hline 2.50 & 1.40 & 1.60 & 1.80 & 2.00 & 2.20 & 2.40 & 2.60 & 2.80 & 3.00 & 3.20 \\
\hline
\end{tabular}

\section{Aortic growth rate}

Normal aorta expands about 1-2 mm over 10 years. The expansion rate of the aneurysm in the ascending aorta is about 
$1.3 \mathrm{~mm} /$ year, with a greater rate of $3.9 \mathrm{~mm} /$ year for descending aorta. The growth rate is proportional to aneurysm diameter. One study has demonstrated that in patients with ascending aorta aneurysms, with initial diameter 35-40 $\mathrm{mm}$ show a mean yearly progression of $2.1 \mathrm{~mm}$, in contrast to 5.6 $\mathrm{mm}$ yearly rate for aneurysm larger than $60 \mathrm{~mm}$ Considering that rapid progression of aneurysm size as a marker of ominous events, elective surgery is generally indicated if dilation rate of pathological aorta is $>10 \mathrm{~mm}$ per year, independently from absolute aortic diameter.

\section{Surgical procedure for the treatment of Ascending aortic aneurysms}

Surgical treatment of the ascending aortic aneurysm compromises endovascular grafting and open surgical procedure. The decision to treat an aneurysm must be made with same rigor for endovascular therapy as for open surgical therapy. The presence of a small thoracic aneurysm is not a valid indication for endovascular therapy just because stent therapy is available. Furthermore, stent deployment for the ascending aortic aneurysm is not approved in most of the countries.

\section{Recommendation for open surgery for ascending aortic aneurysm}

Asymptomatic patients with degenerative thoracic aneurysm who are otherwise suitable candidates and for whom the ascending aorta or aortic sinus diameter is $5.5 \mathrm{~cm}$ or greater, should be evaluated for surgical repair.

Patients with Marfan syndrome or other genetically mediated disorders (Ehler-Danlos syndrome, Turner syndrome, bicuspid aortic valve) should undergo elective surgery at smaller diameter, i.e. 4.0 to $5.0 \mathrm{~cm}$ depending on the condition, to avoid acute dissection or rupture.

\section{Surgical Procedures}

Separate valve and ascending aortic replacement are recommended in patients without significant aortic root dilatation, in elderly patients, or in young patients with minimal dilatation who have aortic valve disease. (Level of Evidence: C)

Patients with Marfan, Loeys-Dietz, and Ehlers-Danlos syndromes and other patients with dilatation of the aortic root and sinuses of Valsalva should undergo excision of the sinuses in combination with a modified David reimplantation operation if technically feasible or, if not, root replacement with valved graft conduit. (Level of evidence: $B$ ). The extent of ascending aortic resection are determined by preoperative imaging and intraoperative findings. For patients with isolated ascending aortic aneurysm, resection and Dacron graft replacement is the recommended procedure.

Whereas, for patients with aortic stenosis requiring valve replacement, the choice of valve is determined by age of the patient, life expectancy, risk of complications related to anticoagulation and reoperation. For patients with aortic regurgitation, repair of the aortic valve with or without root remodeling is preferable if the valve is not severely fibrotic or calcified.

In patients with a dilated aortic root, particularly those with stenotic bicuspid valves, composite valve graft containing either mechanical or biological aortic prosthesis are implanted (Bentall Procedure). However, in elderly patients, sometime ascending aortic aortoplasty may be an acceptable option, if the aortic diameter doesn't exceed $5.0 \mathrm{~cm}$.

In patients with aortic regurgitation and ascending aortic aneurysm, aortic valve repair with root-sparing procedure may be the primary option to consider (Tiron Davide operation). Similarly, Marfan patients with tricuspid aortic valve regurgitation might benefit from a modification of David reimplantation surgery.

\section{CONCLUSION}

Ascending aortic aneurysm is a highly lethal and indolent disease. Usually aneurysmatic aorta grows asymptomatically until it dissects or rupture. Pathophysiology of ascending aortic aneurysm is a complex process. Diagnosis of the ascending aortic aneurysm is made incidentally. So, a high degree of suspicion and diagnostic screening using noninvasive imaging methods allow to detect and treat these vulnerable patients earlier. Conservative treatment could be advised at the initial stage with smaller aortic diameter and in patients with morbidity, high risk factors for negative surgical outcome and who are not suitable for surgical treatment due to other coexisting disease.

Surgical treatment is the gold standard for symptomatic patients and asymptomatic patients with aortic diameter more than $5.5 \mathrm{~cm}$ in otherwise normal patient, while $4.0-5.0 \mathrm{~cm}$ in Marfan patients and patients with genetically mediated process. Postoperative morbidity and mortality has significantly decreased due to better anesthetic management, improved surgical techniques and progress in preoperative and postoperative care. 


\section{REFERENCE}

1. Sans $S$, Kesteloot H, Kromhout D on behalf of the Task Force. Task Force of the European Society of Cardiology on cardiovascular mortality and morbidity statistics. Europe.Eur Heart J 1997; 18: 123148. http://dx.doi.org/ 10.1093/ oxfordjournals.eurheartj.a015434

2. Elefteriades JA. Natural history of thoracic aortic aneurysms: indication for surgery, and surgical versus nonsurgical risks. Ann Thorac Surg 2002; 74 (Suppl):1877-80.

3. Beckman JA. Aortic aneurysms: pathophysiology,epidemiology and prognosis. In: Creager MA, Dzau VJ, Loscalzo J, eds. Vascular Medicine. 2006

4. Beckman JA, Creager MA. Aortic aneurysms: Clinical evaluation. In: Creager MA, Dzau VJ, Loscalzo J, eds. Vascular Medicine. 2006.

5. Coady MA, Rizzo JA, Hammond GL, Mandapati D, Darr U, Kopf GS, et al. What is the appropriate size criterion for resection of thoracic aortic aneurysms? J Thorac Cardiovasc Surg 1997;113:476-91. http://dx.doi.org/10.1016/S00225223(97)70360-X

6. Johansson G, Markstrom U, Swedenborg J. Ruptured thoracic aortic aneurysms: a study of incidence and mortality rates. $J$ Vasc Surg 1995;21:985-958. http://dx.doi.org/10.1016/S0741 5214 (95)70227-X

7. Clouse WD, Hallett JW Jr, Schaff HV, Spittell PC, Rowland CM, et al. Acute aortic dissection: population based incidence compared with degenerative aortic aneurysm rupture. Mayo Clin Proc 2004;79:176-80. http://dx.doi.org/10.4065/79.2.176 PMid:14959911

8. Hagan $P G$, Nienaber CA, Isselbacher EM, Bruckman D, Karavite DJ, Russman PL et al. The international registry of acute aortic dissection (IRAD): new insights into an old disease. JAMA 2000;283(7):897-903. http://dx.doi.org/10.1001/ jama.283.7.897 PMid:10685714

9. Ergin MA, Spielvogel D, Apaydin A, Lansman SL, McCullough $J N$, Galla JD, et al. Surgical treatment of the dilated ascending aorta: when and how? Ann Thorac Surg 1999;67:183439. http://dx.doi.org/10.1016/S0003-4975(99)00439-7

10. Elefteriades JA. Thoracic Aortic Aneurysm: Reading the Enemy's Playbook. Curr Probl Cardiol 2008;33:203-77. http://dx.doi.org/10.1016/j.cpcardiol.2008.01.004 PMid: 18439439

11. Tang PCY, Yakimov AO, Teesdale MA, Coady MA, Dardik A, Elefteriades JA, et al. Transmural inflammation by interferona-producing $T$ cells correlates with outward vascular remodeling and intimal expansion of ascending thoracic aortic aneurysm. FASEB J 2005;19: 1528-30. PMid:16014397
12. Hackmann AE, LeMaire SA, Thompson RW. Long term suppressive therapy: clinical reality and future prospects. In: Elefteriades J, editor. Acute Aortic Conditions. New York: Informa Healthcare, 2007:309-31.

13. Nakashima Y, Kurozumi T, Sueishi K, Tanaka K. Dissecting aneurysm: a clinicopathologic and histopathologic study of 111 autopsied cases. Hum Pathol 1990;21:291-96. http://dx.doi.org/10.1016/0046-8177(90)90229-X

14. Iliopoulos DC, Kritharis EP, Giagini AT, Papadodima SA, Sokolis DP. Ascending thoracic aortic aneurysm are associated with compositional remodeling and vessel stiffening but not weakening in age matched subjects. J Thorac Cardivasc Surg 2009;137:101-09.http://dx.doi.org/10.1016 /j.jtcvs. 2008.07. 023 PMid: 19154911

15. Ishii T, Asuwa N. Collagen and elastin degradation by matrix metalloproteinases and tissue inhibitors of matrix metalloproteinase in aortic dissection. Hum Pathol 2000;31:640-646.http://dx.doi.org/10.1053/hupa.2000.7642 PMid:10872655

16. Nagase H, Woessner JF. Matrix metalloproteinases. J Biol Chem 1999;274:21491-21494. http://dx.doi.org/10.1074 /jbc.274.31.21491

17. Cawston TE. Metalloproteinase inhibitors and the prevention of connective tissue breakdown. Pharmacol Ther 1996;70:16382. http://dx.doi.org/10.1016/0163-7258(96)00015-0

18. Grange JJ, Davies V, Baxter BT. Pathogenesis of abdominal aortic aneurysm: an update and look toward the future. Cardiovasc Surg 1997;5:256-65. http://dx.doi.org/10.1016/ S0967-2109(97)00018-5

19. Lesauskaite V, Tanganelli P, Sassi C, Neri E, Diciolla F, Ivanoviene L, et al. Smooth muscle cells of the media in the dilatative pathology of ascending thoracic aorta: morphology, immunoreactivity for osteopontin, matrix mettaloproteinases, and their inhibitors. Hum Pathol 2001;32:1003-1111. http:// dx.doi.org/10.1053/hupa.2001.27107 PMid:11567232

20. Sinha I, Bethi S, Cronin P, Williams DM, Poelofs $K$, Ailawadi $G$, et al. A biological basis for asymmetric growth in descending thoracic aortic aneurysm: a role for matrix ettaloproteinase 9 and 2. J Vasc Surg 2006;43:342-48. http://dx.doi.org/10.1016/ j.jvs.2005.10.013 PMid:16476613

21. Bunton TE, Biery NJ, Myers L, Gayraud B, Ramirez F, Dietz HC. Phenotypic alteration of vascular smooth muscle cells precedes elastolysis in a mouse model of Marfan syndrome. Circ Res.2001;88(1): 37-43. http://dx.doi.org/10.1161/01. RES. 88.1.37 PMid:11139471

22. Koullias $G$, Ravichandran $P$, Korkolis $D$, Rimm $D L$, Elefteriades JA. Increased tissue microarray matrix mettaloproteinase expression favors proteolysis in thoracic aortic aneurysms and dissections. Ann Thorac Surg 2004;78: 
2106-11. http://dx.doi.org/10.1016/j.athoracsur.2004.05.088 PMid:15561045

23. Schonbeck U, Sukhova GK, Gerdes N, Libby P. T(H)2 predominant immune responses prevail in human abdominal aortic aneurysm. Am J Pathol 2002;161:499-506. http://dx.doi.org/10.1016/S0002-9440(10)64206-X

24. Groenink $M$, Langerak $S E$, Vandavel $E$, van der Wall EE, Mulder BJM, van der Wal AC, et al. The influence of aging and aortic stiffness on permanent dilatation and breaking stress of the thoracic descending aorta. Cardivasc Res 1999;43:471-80. http://dx.doi.org/10.1016/S0008-6363(99)00095-4

25. Elefteriades JA. Preface. In: Elefteriades JA, editor. Diseases of the aorta. Cardiol Clin 1999;17:i-850.

26. Juvonen T, Ergin MA, Galla JD, Lansman SL, McCullough JN, Levy D, et al. Prospective study of the natural history of thoracic aortic aneurysms. Ann Thorac Surg 1997;63:1533-45. http://dx.doi.org/10.1016/S0003-4975(97)00414-1

27. Vorp DA, Vande Geest JP. Biomechanical determinants of abdominal aortic aneurysm rupture. Arterioscler Thromb Vasc Biol2005;25:1558-66. http://dx.doi.org/ 10.1161/ 01.ATV. 0000174129.77391.55 PMid:16055757

28. Lehmann ED, Gosling RG, Parker JR, de-Silva T, Taylor MG. A blood pressure independent index of aortic distensibillity. $\mathrm{Br} J$ Radiol 1993;66:126-31. http://dx.doi.org/10.1259/0007-128566-782-126 PMid:8457825

29. Bramwell JC, Hill AY. Velocity of transmission of the pulsewave and elasticity of arteries. Lancet 1922; 891-892. http://dx. doi. org/10.1016/S0140-6736(00)95580-6

30. Lehmann ED. Clinical value of aortic pulse wave velocity measurement. Lancet 1999;354:528-529. http://dx.doi.org/ $10.1016 / S 0140-6736(99) 00179-8$

31. Koullias G, Modak R, Tranquilli M, Korkolis DP, Barash P, Elefteriades JA. Mechanical deterioration underlies malignant behavior of aneurismal human ascending aorta. J Thorac Cardiovasc Surg 2005;130:677-83. http://dx.doi.org/10.1016/ j.jtcvs.2005.02.052 PMid:16153912

32. Okamoto RJ, Wagenseil JE, DeLong WR, Peterson SJ, Kouchoukos NT, Sundt TM III. Mechanical properties of dilated human ascending aorta. Ann Biomed Eng 2002;30:614-35. http://dx.doi.org/10.1114/1.1484220

33. Vorp DA, Schiro BJ, Ehrlich MP, Juvonen TS, Ergin MA, Griffith BP. Effect of aneurysm on the tensile strength and biomechanical behavior of the ascending thoracic aorta. Ann Thorac Surg 2003; 75:1210-14. http://dx.doi.org/10.1016 /S0003-4975(02)04711-2

34. Savolainen A, Keto P, Hekali P, Nislua L, Kaitila I, Viitasalo M, et al. Aortic distensibility in children with the Marfan syndrome. Am J Cardiol 1992; 70:691693. http://dx.doi.org/10.1016 10002-9149(92)90215-K

35. Groenink $M$, de Roos A, Mulder BJ, Verbeeten $B J$, Timmermans $J$, Zwinderman AH, et al. Biophysical properties of the normal-sized aorta in patients with Marfan syndrome: evaluation with MR flow mapping. Radiology 2001;219:53540. http://dx.doi.org/10.1148/radiology.219.2.r01ma01535 PMid: 11323484

36. Mohan D, Melvin JW. Failure properties of passive human aortic tissue. II-Biaxial tension tests. J Biomech 1983;16:3144. http://dx.doi.org/10.1016/0021-9290(83)90044-1

37. Mitchell GF, Parise H, Benjamin EJ, Larson MG, Keyes MJ, Vita JA, et al. Changes in the arterial stiffness and wave reflection with advancing age in healthy men and women: the Framingham Heart Study. Hypertension 2004;43:1239-45. http://dx.doi.org/10.1161/01.HYP.0000128420.01881.aa PMid: 15123572

38. Mohr-Kahaly S, Erbel R. Advantages of biplane and multiplane transesophageal echocardiography for the morphology of the aorta. Am J Card Imaging 1995; 9: 11520. PMid:779537

39. Elefteriades JA, Farkas EA. Thoracic aortic aneurysm. Clinically pertinent controversies and uncertainties. J Am Coll Card 2010;55:841-55. http://dx.doi.org/10.1016/j .jacc.2009. 08.084 PMid:20185035

40. Sommer T, Fehske W, Holzknecht N, Smekal AV, Keller E, Lutterbey $G$, et al. Aortic dissection: a comparative study of diagnosis with spiral CT, multiplanar transesophageal echocardiography, and MR imaging. Radiology 1996; 199:34752. http://dx.doi.org/10.1148/ radiology. 199.2.86687 76 PMid:8668776

41. Moore AG, Eagle KA, Bruckman D, Moon BS, Malouf JF, Fattori $R$, et al. Choice of computed tomography, transesophageal echocardiography, magnetic resonance imaging, and aortogrpahy in acute aortic dissection: International registry of Acute aortic dissection (IRAD). Am J Cardiol 2002;89:1235-38. http://dx.doi.org/10.1016/S00029149(02)02316-0

42. Schlosser FJ, Mojibian HR, Dardik A, Verhagen HJ, Moll FL, Muhs BE. Simultaneous sizing and preoperative risk stratification for thoracic endovascular aneurysm repair: role of gated computed tomography. J Vasc Surg 2008;48:56170.http://dx.doi.org/10.1016/j.jvs.2008.04.055 PMid: 18586438

43. Nienaber CA, von Kodolitsch Y, Peterson B, Loose R, Helmchen $A$, Spielmann $R$. Intramural hemorrhage of the aorta: diagnostic and therapeutic implications. Circulation 1995;92:1465-72. http://dx.doi.org/10.1161/01.CIR.92.6.1465 PMid: 7664428 
44. Schmidta M, Theissen P, Klempt G, Deutsch HJ, Baer FM, Dietlein $M$, et al. Long-term follow-up of 82 patients with chronic disease of the thoracic aorta using spin-eco and cine gradient magnetic resonance imaging. Magn Reson Imaging 2000;18:795-806. http://dx.doi.org/10.1016/S0730-725X (00)00169-7

45. Barker AJ, Staehle F, Bocl J, Jung BA, Markl M. Analysis of complex cardiovascular glow with three-component acceleration-encoded MRI. Magn Reson Med 2012;67 :5061.ttp://dx.doi.org/10.1002/mrm.22974 PMid:21590722

46. Aquaro GD, Ait-Ali L, Basso ML, Lombardi M, Pingitore A, Festa PL. Elastic properties of aortic wall in patients with bicuspid aortic valve by magnetic resonance imaging. Am J of Cardiol 2011;108:81-87. http://dx.doi.org/10.1016/j. amjcard. 2011.03.005 PMid:21529726

47. Shores J, Berger KR, Murphy EA, Pyeritz RE. Progression of aortic dilatation and the benefit of long-term beta-adrenergic blockade in Marfan's syndrome. N Engl J Med. 1994;330: 133541.http://dx.doi.org/10.1056/NEJM199405123301902 PMid:8152445

48. Chiu HH, Wu MH, Wang JK, Lu CW, Chiu SN, et al. Losartan added to â-blockade therapy for aortic root dilation in Marfan syndrome: a randomized, open-label pilot study. Mayo Clin Proc2013;88:271-76. http://dx.doi.org/10. 1016/j. mayocp. 2012.11.005 PMid:23321647

49. Mosorin M, Juvonen J, Biancari F, Satta J, Surcel HM, Leinonen $M$, et al. Use of doxycycline to decrease the growth rate of abdominal aortic aneurysms: a randomized, doubleblind, placebo-controlled pilot study. J Vasc Surg 2001;34:606-10. http://dx.doi.org/10.1067/mva.2001.117891 PMid:11668312

50. Abdul-Hussien H, Hanemaaijer R, Verheijen JH, van Bockel $J H$, Geelkerken RH, Lindeman JH. Doxycycline therapy for abdominal aneurysm: improved proteolytic balance through reduced neutrophils content. J Vasc Surg 2009;49:74149. http://dx.doi.org/10.1016/j.jvs.2008.09.055 PMid:19268776

51. Davies RR, Gallo A, Coady MA, Tellides G, Botta DM, Burke B, et al. Coe MP, Kopf GS, Elefteriades JA. Novel measurement of relative aortic size predicts rupture of thoracic aortic aneurysms. Ann Thorac Surg 2006;81:169-77.http://dx. doi.org/10.1016/j.athoracsur.2005.06.026 PMid:16368358

52. Pressler V, McNamara JJ. Thoracic aortic aneurysm. Natural history and treatment. J Thorac Cardiovasc Surg 1980;79:48998. PMid:7359927

53. Zehr KJ, Orszulak TA, Mullany CJ, Matloobi A, Daly RC, Dearani JA et al. Surgery for aneurysms of the aortic root: A 30Year Experience. Circulation 2004;110:1364-71. http://dx.doi. org/10.1161/01.CIR.0000141593.05085.87 PMid:15313937
54. Achneck HE, Rizzo JA, Tranquilli M, Elefteriades JA. Safety of thoracic aortic surgery in the present era. Ann Thorac Surg 2007;84:1180 85.http://dx.doi.org /10. 1016/j.athoracsur. 2007.05.038 PMid:17888967

55. Schmid FX, Bielenberg K, Schneider A, Haussler A, Keyser A, Birnbaum D. Ascending aortic aneurysm associated with bicuspid and tricuspid aortic valve: involvement and clinical relevance of smooth muscle cell apoptosis and expression of cell death-initiating proteins. Eur J Cardiothorac Surgy 2003;23:53743. http://dx.doi.org/10.1016/S1010-7940 (02) 00833-3

56. Dapunt OE, Galla JD, Sadeghi AM, Lansman SL, Mezrow CK, de Asla RA et al. The natural history of thoracic aortic aneurysms. J Thorac Cardiovasc Surg 1994;107:132333. PMid: 8176976

57. Coady MA, Rizzo JA, Hammond GL, Kopf GS, Elefteriades JA. Surgical intervention criteria for thoracic aortic aneurysms: a study of growth rates and complications. Ann Thorac Surg 1999;67:192226. http://dx.doi.org/10.1016/S0003-4975(99) 00431-2

58. Hannuksela $M$, Lundqvist $S$, Carlsberg B. Thoracic aorta: dilated or not? Scand Cardiovasc J 2006;40:175-8. http://dx.doi.org/ 10.1080/1401743 0600565 999. PMid :16798665

59. Coady MA, Rizzo JA, Hammond GL, Mandapati D, Darr U, Kopf GS et al. What is the appropriate size criterion for resection of thoracic aortic aneurysms? $J$ Thorac Cardiovasc Surg1997;113:476-91.http://dx.doi.org/10.1016/S0022-5223 (97)70360-X

60. Masuda Y, Takanashi K, Takasu J, Morooka N, Inagaki Y. Expansion rate of thoracic aortic aneurysms and influencing factors. Chest 1992;102:461-6.http://dx.doi.org/10.1378/ chest. 102.2.461 PMid:1643933

61. Shimada I, Roonery SJ, Pagano D, Farneti PA, Davies P, Guest $P J$ et al. Prediction of thoracic aortic aneurysm expansion: validation of formulae describing growth. Ann Thorac Surg 1999;67:1968-70. http://dx.doi.org/10.1016/S0003-4975(99) 00435-X

62. Judge DP, Dietz HC. Marfan's syndrome. Lancet. 2005;366 :1965-1976. http://dx.doi.org/10.1016/S0140-6736(05)67789-6

63. Hiratzka LF, Bakris GL, Beckman JA, Bersin RM, Carr VF, Casey DE et al. 2010 ACCF/AHA/AATS/ACR/ASA /SCA/SCAI/ SIR/STS/SVM guidelines for the diagnosis and management of patients with Thoracic Aortic Disease. Circulation 201;121: e266-e369. 